\title{
The Impact of Hatha Yoga Practice on Flexibility: A Pilot Study
}

\author{
Maja Petrič ${ }^{\star}$, Renata Vauhnik and Miroljub Jakovljević \\ Cesta v log 24, Ljubljana, Slovenia \\ *Corresponding author: Maja Petrič, Cesta v log 24, Ljubljana, Slovenia 1351,Slovenia, Tel: +386-31-744-564; E-mail: maja.53c@gmail.com \\ Rec date: Feb 19, 2014; Acc date: Apr 09, 2014; Pub date: Apr 11, 2014
}

Copyright: () 2014 Petrič M, et al. This is an open-access article distributed under the terms of the Creative Commons Attribution License, which permits unrestricted use, distribution, and reproduction in any medium, provided the original author and source are credited

\section{Abstract}

Background: In modern times people have to cope daily with various challenges that can leave an impact on their body flexibility. Physical inactivity is one of the reasons for the diminishment of our natural body flexibility. The consequence of physical inactivity is decreased flexibility of soft tissues surrounding joints. Simple yoga techniques including body postures and breathing techniques can restore natural body flexibility.

Methods: Our study involved 9 young healthy females (mean age $23.8 \pm 2.9$ years). The training program was held twice a week over a period of five months. The program included therapeutic yoga exercises, with the aim of increasing joint mobility as well as stretching shortened skeletal muscles. We used goniometric measurement procedures for measuring joint mobility (for shoulder, hip and ankle joints), linear measurement procedures for measuring the active mobility of the thoracolumbar part of the spine and specific assessing tests for evaluating skeletal muscle shortness. Measurements of body flexibility were taken three times over the five months period.

Results: The results obtained by measuring joint mobility showed significant increase of mobility in elevation through abduction, shoulder retroflexion, hip flexion, internal and external hip rotation, dorsal flexion and inversion of the ankle. The mobility of the thoracolumbar part of the spine was increased in all the measured movements: flexion, extension, lateral flexion and rotation of the spine. There was also a significant improvement in the flexibility of $\mathrm{m}$. Soleus, $\mathrm{m}$. Gastrocnemius, $\mathrm{m}$. Rectus femoris, knee flexors and $\mathrm{m}$. Pectoralis major. A significant improvement in body flexibility was also confirmed by the "Back Scratch Test" and the "Sit and Reach Test".

Conclusion: Improved body flexibility is one of the most obvious and quickly achieved effects of regular hatha yoga practice. The results of this study confirm that regular practice of yoga has a significant effect on body flexibility in young healthy women, which is particularly obvious in measurements of the increase of the flexibility of skeletal muscles.

Keywords: Yoga; Flexibility; Therapeutic effects

\section{Introduction}

Regular physical activity is one of the bases of a healthy lifestyle. It creates and maintains general well-being, physical and mental health, as well as promoting human performance in all areas of life. Physical inactivity is one of the reasons for the diminishment of our natural body flexibility and strength; it dulls our senses and generally reduces the awareness of our own body. Eventually, all this results in poor posture, which, by it, can lead to pain and injury. In addition to reduced physical activity, stress has a large and equally negative impact on health, and stress is becoming quite common nowadays. We are not always able to influence the external environment, but we can control our body, breathing, mind and emotions, and thus can prevent or at least mitigate the negative effects of stress on our health. This is probably the most common reason why yoga and other similar forms of exercise are so accepted and popular in modern societies. Yoga enables us to reconnect the body, breath and mind into a whole and thus improve awareness of our own body [1].

Mobility is defined as the ability to move body structures or parts of the body through the existing range of motion for a functional activity (functional range of motion) [2]. Mobility referring to the functional range of motion is strongly associated with joint integrity as well as flexibility. The term flexibility in this context means the elasticity of soft tissues that cross or surround joints (muscles, tendons, fascia, articular capsule, ligaments, nerves, blood vessels, skin), and is absolutely necessary for painless movement of the body [2]. In most situations flexibility does not depend solely on the actual length of soft tissues, for example muscle or muscle fibers forming the muscles. The length of an active muscle, its tone and the length of its stretch also depend on proprioceptive nerve endings in the muscle [3]. The length of stretch, regarding the adequacy, safety and functionality of stretch, is therefore controlled by the nervous system, which consequently affects the range of motion of the joint surrounded by the soft tissue [3].

There can be many different reasons for reduced range of motion, but one of them definitely is muscle shortness, which occurs as a result of physical inactivity and putting irregular or excessive pressure on muscles and other soft tissues crossing or surrounding joints. However, not all the muscles respond to the above-mentioned pathological stimuli with shortening. This response is typical for predominantly tonic, postural muscles whose main function is to maintain the posture [4]. Another group of muscles, mainly phasic muscles, is involved in carrying movements in daily activities. Those muscles respond by weakness under incorrect or excessive pressure [4]. If there is shortness of tonic muscles, this aggravates the weakness of phasic muscles, and vice versa. Therefore there has to be a balanced 
and coordinated action of both muscle groups for the normal functioning of the musculoskeletal system.

Improved flexibility is one of the most obvious and quickly achieved effects of regular yoga practice, since this is based on gradual stretching of muscle and connective tissue around bones and joints [5], static retention of yoga poses and movements of joints throughout the entire existing range of motion [6]. The latter provide straight-line compression and lubrication of articular cartilage by the synovial fluid, thereby bringing fresh nutrients and oxygen to those parts of joint cartilage which are rarely used in everyday activities [6].

In this research we examine the quantitative impact of regular yoga practice on body flexibility in young healthy females. Most of the published studies of the impact of yoga practice on flexibility only measure the general flexibility of the upper and/or lower part of the body. The most commonly used tests are versions of the "Sit and Reach Test" [7-10] and the "Back Scratch Test" [8]. Among the studies taken into consideration none observes changes in mobility of individual joints by goniometric measurement procedures, isolated flexibility of the spine or the impact of yoga practice on the flexibility of individual skeletal muscles.

\section{Materials and Methods}

Healthy, young subjects were recruited by flyer from our local community. No incentives were offered other than the yoga classes and physiotherapeutic testing. Following approval of The National Medical Ethics Committee of the Republic of Slovenia, written informed consent was obtained from 10 young healthy females who volunteered to participate. All participants were healthy, and did not present recent skeletal or muscle injuries. Furthermore, all participants fulfilled the condition for participation in this study, namely that they had not participated in yoga or any other activities aimed at increasing flexibility for a period of 6 months prior to the start of our training program. Nine females (mean age $23.8 \pm 2.9$ years) completed the study; one subject dropped out during the second half of the study and declined to perform last testing.

In present study we performed the so-called hatha yoga. The training program of hatha yoga was held twice a week (in 75 minutes sessions) over a period of five months, performed solely for the purposes of this study. The training was led by certified yoga teachers. The program included therapeutic yoga exercises aimed at increasing joint mobility as well as stretching shortened skeletal muscles. Each training session consisted of 10 minutes of pranayama (controlled breathing exercises), 10 minutes of warm-up exercises, 45 minutes of asana practice (yoga poses) and 10 minutes of relaxation.

We used goniometric measurement procedures [11] for measuring joint mobility. An universal goniometer (Baseline measurement instruments, ZDA) was used to measure the range of motion at the shoulder (elevation through anteflexion, elevation through abduction, retroflexion, internal and external rotation), hip (flexion, extension, abduction, adduction, internal and external rotation) and ankle joints (dorsal/plantar flexion, eversion and inversion) bilaterally. All goniometric measurements were passive, performed by examiner [11].

The active mobility of the thoracolumbar part of the spine was measured by linear measurement procedures [11]. Flexion, extension and lateral flexion range of motion recorded was difference between initial and final measurement of distance between the spinous process of C7 and S1 vertebra in an erect posture and final flexion/extension/ lateral flexion of the spine. For measuring rotation of the thoracolumbar spine a measuring tape was aligned with $0 \mathrm{~cm}$ at acromion and maintained against subject's back to pelvic opposite spina iliaca anterior superior. Rotation range of motion was difference between length measured at erect sitting posture (initial measurement) and length measured at end of rotation motion (final measurement) [11].

Specific muscle length tests were used for evaluating skeletal muscle shortness $[4,11]$. For measurement of $\mathrm{m}$. Soleus length the ankle dorsal flexion with the knee flexed was performed [11]. Same motion, but with the knee extended, was used for measuring the length of $\mathrm{m}$. Gastrocnemius. The shortness of $\mathrm{m}$. Rectus femoris was assessing by knee flexion while hip was extended in supine position [11]. Hamstring muscles (m. Semimembranosus, $\mathrm{m}$. Semitendinosus and $\mathrm{m}$. Biceps femoris) shortness were assessing with maximal hip flexion maintaining the knee extended [11]. With shoulder elevation through abduction we tested the flexibility of $\mathrm{m}$. Pectoralis major [11]. For subject all motions at muscle length testing were passive, performed by examiner [11].

We also used the "Back Scratch Test" [11,12] for evaluating overall shoulder flexibility, and the "Sit and Reach Test" [11,13,14] for low back and hamstring flexibility. The "Back Scratch Test" involves reaching behind the head with one hand and behind the back with the other. We measure the distance between (or overlap of) the middle fingers behind the back [12]. The "Sit and Reach Test" was performed by having the subject assume the long sitting posture and reach forward with both hands as far as possible, not allowing the knees to flex. A score was given based on the most distant point reached by both hands [14].

All the above-mentioned measurements of body flexibility were taken three times over the five months period; first at the beginning of the training program, next after 2 months of training and finally, at the end of the 5 months training program. All the measures were taken prior the yoga session or at least one day after it. Since the flexibility of soft tissues in women is subject to minimal changes in relation to the phase of the menstrual cycle [15], we measured all participants in the same phase of the cycle, on the 6th day of the ovulation.

The results are presented with descriptive statistics (mean range of motion \pm standard deviation (SD)). We compared baseline measurements to the results obtained after two months of training, and after five months of training (change of motion in $\% \mathrm{~cm}$ ). Clinically significant changes in flexibility were $\geq 5^{\circ}$. To analyze the differences between periods we used the analysis of variance for repeated measurements (ANOVA, $\mathrm{p} \leq 0.05$ ) and Student's " post hoc « $\mathrm{t}$ test with Bonferroni correction ( $\mathrm{p} \leq 0.05)$. The analysis was performed with the statistical program MedCalc (version 11.1.0.0).

\section{Results}

The average attendance at the training was $77.5 \%$ (27.9 \pm 4.0 hours of a total of 36 hours of yoga practice). The attendance was higher in the first part of the training program (before the 2nd measurement).

As shown by the first measurement, all participants had some deviations from the normal range of motion [11] at the beginning of the training program (Table 1). For most of the measurements the flexibility increased steadily on both measured sides and there was a reduction in the differences between the range of motion on the left and right measured side through the research. 
Citation: Petric M, Vauhnik R, Jakovljevic M (2014) The Impact of Hatha Yoga Practice on Flexibility: A Pilot Study. Altern Integ Med 3: 160. doi:

Page 3 of 5

The results obtained by measuring joint mobility showed significant increase of mobility in elevation through abduction, shoulder

\begin{tabular}{|l|l|l|l|}
\hline Joint mobility $\left({ }^{\circ}\right)$ & 1. & 2. & 3. \\
\hline Shoulder elevation through abduction & $164.4 \pm 6.2$ & $167.5 \pm 8.5$ & $172.5 \pm 5.8^{*}$ \\
\hline Shoulder retroflexion & $44.7 \pm 5.4$ & $47.8 \pm 4.5$ & $50.0 \pm 4.4^{*}$ \\
\hline Hip flexion & $107.8 \pm 7.9$ & $112.8 \pm 5.3$ & $114.4 \pm 6.4^{*}$ \\
\hline Internal hip rotation & $38.6 \pm 4.3$ & $42.2 \pm 5.1$ & $43.9 \pm 6.6^{*}$ \\
\hline External hip rotation & $31.1 \pm 3.9$ & $35.0 \pm 6.0$ & $36.1 \pm 4.9^{*}$ \\
\hline Ankle dorsal flexion & $7.8 \pm 3.0$ & $12.5 \pm 6.3^{*}$ & $17.2 \pm 6.3^{*}$ \\
\hline Ankle inversion & $20.0 \pm 6.0$ & $24.7 \pm 6.8$ & $26.7 \pm 6.2^{*}$ \\
\hline
\end{tabular}

Table 1: Improvements in mobility (mean values \pm SD) of shoulder, hip and ankle joints before training (1. measurement), after two months of training (2. measurement) and at the end of the 5 months training program (3. measurement).

The mobility of the thoracolumbar part of the spine was increased in all the measured movements: flexion, extension, lateral flexion and rotation of the spine (Table 2).

\begin{tabular}{|l|l|l|l|}
\hline Spine mobility $(\mathrm{cm})$ & 1. & 2. & 3. \\
\hline Flexion & $11.1 \pm 1.5$ & $12.0 \pm 1.8$ & $12.7 \pm 1.6^{*}$ \\
\hline Extension & $6.9 \pm 2.6$ & $7.7 \pm 2.0$ & $8.4 \pm 2.8^{*}$ \\
\hline Lateral flexion & $1.2 \pm 0.5$ & $1.7 \pm 0.6^{*}$ & $2.3 \pm 0.7^{*}$ \\
\hline Rotation & $6.2 \pm 1.6$ & $6.9 \pm 1.2^{*}$ & $7.2 \pm 1.0^{*}$ \\
\hline
\end{tabular}

Table 2: Improvements in mobility (mean values $\pm \mathrm{SD}$ ) of thoracolumbar part of the spine before training (1. measurement), after two months of training (2. measurement) and at the end of the 5 months training program (3. measurement).

There was a significant improvement in the flexibility of $\mathrm{m}$. Soleus, $\mathrm{m}$. Gastrocnemius, m. Rectus femoris, knee flexors and $\mathrm{m}$. Pectoralis major (Table 3).

\begin{tabular}{|l|l|l|l|}
\hline Muscle flexibility ( $\left.{ }^{\circ}\right)$ & 1. & 2. & 3. \\
\hline $\begin{array}{l}\text { m. Soleus } \\
\text { (ankle dorsal flexion with the knee } \\
\text { flexed) }\end{array}$ & $7.8 \pm 3.0$ & $12.5 \pm 6.3^{*}$ & $17.2 \pm 6.3^{*}$ \\
\hline $\begin{array}{l}\text { m. Gastrocnemius } \\
\text { (ankle dorsal flexion with the knee } \\
\text { extended) }\end{array}$ & $0.6 \pm 2.8$ & $3.9 \pm 4.9^{*}$ & $7.2 \pm 6.3^{*}$ \\
\hline $\begin{array}{l}\text { m. Rectus femoris } \\
\text { (knee flexion with the hip extended) }\end{array}$ & $55.6 \pm 9.7$ & $58.6 \pm 8.1$ & $63.6 \pm 6.2^{*}$ \\
\hline $\begin{array}{l}\text { knee flexors } \\
\text { (hip flexion with the knee extended) }\end{array}$ & $80.3 \pm 7.9$ & $93.9 \pm 8.1^{*}$ & $102.5 \pm 12.7^{*}$ \\
\hline $\begin{array}{l}\text { m. Pectoralis major } \\
\text { (shoulder elevation through abduction) }\end{array}$ & $164.4 \pm 6.2$ & $167.5 \pm 8.5$ & $172.5 \pm 5.8^{*}$ \\
\hline
\end{tabular}

Table 3: Improvements in flexibility (mean values \pm SD) of skeletal muscles before training (1. measurement), after two months of training (2. measurement) and at the end of the 5 months training program (3. measurement). 
Page 4 of 5

A significant improvement in body flexibility was also confirmed by the "Back Scratch Test" for the upper body and the "Sit and Reach Test" for the lower body (Table 4).

\begin{tabular}{|l|l|l|l|}
\hline General flexibility $(\mathrm{cm})$ & 1. & 2. & 3. \\
\hline Back Scratch Test & $4.9 \pm 7.5$ & $6.2 \pm 6.7^{*}$ & $7.4 \pm 6.3^{*}$ \\
\hline Sit and Reach Test & $0.1 \pm 10.0$ & $7.8 \pm 8.0^{*}$ & $12.9 \pm 6.6^{*}$ \\
\hline
\end{tabular}

Table 4: Improvements in general flexibility (mean values \pm SD) of the upper and lower part of the body before training (1. measurement), after two months of training (2. measurement) and at the end of the 5 months training program (3. measurement).

\section{Discussion}

Improved body flexibility is one of the most obvious and quickly achieved effects of regular hatha yoga practice, which was confirmed also by the results of our study. As found in previous studies, regular yoga practice helps to increase joint mobility primarily in older people [16]. Thus in our study, focusing on young and healthy participants, a significant improvement in joint mobility had not been expected. However, the mobility of some joints did increase significantly. Given that the participants were young, healthy persons with no recent skeletal or muscle injuries, we may assume that the cause of initially limited joint mobility was not reduced sliding of articulating surfaces. The reasons can be found in the shortness of the soft tissues surrounding the joints, especially in reduced skeletal muscle flexibility.

Among all the forms of yoga, hatha yoga is the one that gives the most priority to the importance of physical fitness. Based on the interpretation of the word hatha - in Sanskrit the syllable "ha" means the sun, male energy, strength, and "tha" means the moon, female energy, flexibility [1] - it can be summarized that hatha yoga is a dynamic balance between strength and flexibility, which concerns the physical, mental and also emotional level [1].

Some of the published research papers studied the effect of regular yoga practice on the general flexibility of the upper and/or lower body. Some of these studies lasted for 8 weeks [7-9], so their results can be compared with the results of our first mid-term measurement, which was also carried out after 8 weeks of practicing yoga. In the abovementioned studies lower body flexibility improved by $4.1 \mathrm{~cm}$ [7], 0.9 cm (used test version: "Chair Sit and Reach Test") [8] and $10.0 \mathrm{~cm}$ [9] after 8 weeks of training program. One study also measured flexibility of the upper body by "Back Scratch Test" and there the increase of flexibility was $1.3 \mathrm{~cm} \mathrm{[8].} \mathrm{Our} \mathrm{results} \mathrm{at} \mathrm{the} \mathrm{2nd} \mathrm{measurement} \mathrm{(after} 8$ weeks training program) showed for $7.7 \pm 5.4 \mathrm{~cm}$ greater flexibility in "Sit and Reach Test" and by $1.3 \pm 1.5 \mathrm{~cm}$ greater flexibility in "Back Scratch Test". We found no other similar research monitoring the impact of regular yoga practice on joint and spine mobility or specific skeletal muscle flexibility, to compare with the results obtained in this study.

With yoga practice we can relax many physical dysfunctions and improve the flexibility of the body. Compared to physiotherapy procedures, yoga, with its static-dynamic procedures, can also be discussed as a means of "self-mobilization" of the nervous system and joints of spine and extremities [17]. In general yoga practice is performed slowly and gradually, in a closed kinetic chain (specific poses or static postures), which may include active stretching, isometric muscle contractions, enhancing concentration and proper breathing patterns. Conceptually, we can conclude that both physiotherapy and yoga, each through its own procedures, improve muscle strength, increase joint mobility and soft tissue flexibility, mobilize the nervous system, improve body posture, improve proprioception and thereby encourage better awareness of the body, releasing trigger points and relieving pain [17]. The National Institutes of Health $(\mathrm{NIH})$ and the National Center for Complementary and Alternative Medicine (NCCAM) acknowledged yoga as a form of complementary and alternative medicine in the category of "Mind and Body Practices" [18]. According to the NCCAM's definition yoga therapy is defined as a process of empowering individuals to progress toward improved health and well-being through the application of the philosophy and practice of yoga [19].

In recent years there have been a growing number of studies showing that regular exercise of hatha yoga increases muscle strength and flexibility [20]. Of course, various styles of yoga can differ greatly. And depending on the intensity of each yoga style the effects (e.g. increase of mobility) can be very different as well. One study compares the effects of two different styles of yoga: ashtanga and hatha yoga [21]. Ashtanga yoga is a physically demanding form of yoga in which the majority of poses are dynamically linked in sequences, such as Sun Salutation, also used in hatha yoga [22]. The study used the "Sit and Reach Box" test for measuring the flexibility. A group which had practiced ashtanga yoga improved the flexibility of the body by 20 percent, while a group which had practiced hatha yoga improved it by 14 percent.

Most of the measurements in our study showed greater improvement in the first part of the training program compared to the period between the intermediate and the final measurements. There may be several reasons for that. Most participants in the study practiced yoga for the first time. Therefore a possible explanation for the difference in the progress between the periods is that the participants' bodies responded better and more quickly to stretching and relaxation in yoga practice in the first weeks of training, and then at some point their bodies got used to this kind of exercise and the progress slowed. Another reason may be higher attendance in the first part of the training program (8 percent higher attendance). And the third reason could be a few days break of guided exercise in the second part of the research program, because of the holidays.

In terms of increasing flexibility the aim of yoga is not hypermobility but an adequate level of flexibility enabling us to easier and better use our muscles in everyday activities. For this we need appropriate flexibility of muscles that maintain posture (tonic muscles) and adequately strengthened muscles which are responsible for the movement of the distal segments of the body (phasic muscles) [4]. In our study yoga proved an effective form of exercise, at least from the viewpoint of the postural muscles.

The disadvantages of the majority of research of the effects of yoga on the body (including ours) are a small sample of subjects, varying duration of the research and different methods of measuring body 
flexibility. Therefore it would be important to explore this area through studies of standard duration using standard measurement procedures, especially on a larger sample of subjects. It would also be meaningful to further explore the effects of regular yoga practice on flexibility as well as its impact on stability and protection of the joints in which mobility is increasing. Further research into the effects of yoga practice in various pathologies and injuries meant to enhance the usefulness of yoga techniques in physiotherapy would also be welcome.

\section{Conclusion}

The results of this study confirm that regular practice of hatha yoga has a significant effect on body flexibility in young healthy women. This is particularly obvious in measurements of the increase of the skeletal muscles flexibility.

\section{Acknowledgements}

The author thanks to the Faculty of Health Sciences Ljubljana, Miroljub Jakovljević, PhD, PT, and Renata Vauhnik, PhD, PT, for inspiring attitude and professional assistance in the creation of this research. Special thanks are due to yoga teacher Blaž Bertoncelj who has enabled the implementation of the training program and take care of the professional conducting of yoga practice.

\section{References}

1. Schöps I (2010) Yoga: Theory and practice for beginners and advanced students. Bath: Parragon Book Service Ltd.

2. Kisner C, Colby LA (2007) Therapeutic exercise: foundations and techniques. (5thedn), Philadelphia: F. A. Davis Company.

3. Kaminoff L, Matthews A (2012) Yoga anatomy. (2ndedn), Campaign (IL): Human Kinetics.

4. Schneider W, Spring H, Tritschler T (1992) Mobility: theory and practice. New York: Thieme Medical Publishers.

5. Woodyard C (2011) Exploring the therapeutic effects of yoga and its ability to increase quality of life. Int J Yoga 4: 49-54.

6. McCall (2007) Yoga as medicine: the yogic prescription for health \& healing. New York: Random house, Inc.

7. Tran MD, Holly RG, Lashbrook J, Amsterdam EA (2001) Effects of Hatha Yoga Practice on the Health-Related Aspects of Physical Fitness. Prev Cardiol 4: 165-170.
8. Van Puymbroeck M, Payne LL, Hsieh PC (2007) A phase I feasibility study of yoga on the physical health and coping of informal caregivers. Evid Based Complement Alternat Med 4: 519-529.

9. Telles S, Dash M, Naveen KV (2009) Effect of yoga on musculoskeletal discomfort and motor functions in professional computer users. Work 33: $297-306$

10. Cowen VS (2010) Functional fitness improvements after a worksitebased yoga initiative. J Bodyw Mov Ther 14: 50-54.

11. Berryman Reese N, Bandy WD (2002) Joint range of motion and muscle length testing. Philadelphia, Pa: W.B. Saunders Company.

12. Rikli RE, Jones CJ (2013) Development and validation of criterionreferenced clinically relevant fitness standards for maintaining physical independence in later years. Gerontologist 53: 255-267.

13. Wells KF, Dillon EK (1952) The sit-and-reach. A test of back and leg flexibility. Res Q 23: 115-118.

14. Ayala F, Sainz de Baranda P, De Ste Croix M, Santonja F (2012) Reproducibility and criterion-related validity of the sit and reach test and toe touch test for estimating hamstring flexibility in recreationally active young adults. Phys Ther Sport 13: 219-226.

15. Melegario SM, Simao R, Vale RGS, Batista LA, Novaes JS (2006) The influence of the menstrual cycle on the flexibility in practioners of gymnastics at fitness centers. Rev Bras Med Esporte 12: 114-117.

16. Gonçalves LC, Vale RG, Barata NJ, Varejão RV, Dantas EH (2011) Flexibility, functional autonomy and quality of life (QoL) in elderly yoga practitioners. Arch Gerontol Geriatr 53: 158-162.

17. Posadzki P, Parekh S (2009) Yoga and physiotherapy: a speculative review and conceptual synthesis. Chin J Integr Med 15: 66-72.

18. National Center for Complementary and Alternative Medicine (2008) What is complementary and alternative medicine?

19. Taylor MJ (2007) What is yoga therapy? IAYT offers a definition for the field. YTIP, 3: 3 .

20. Raub JA (2002) Psychophysiologic effects of Hatha Yoga on musculoskeletal and cardiopulmonary function: a literature review. J Altern Complement Med 8: 797-812.

21. Cowen VS, Adams TB (2005) Physical and perceptual benefits of yoga asana practice: results of a pilot study. J Bodywork Movement Ther 9: 211-219.

22. Broad WJ (2012) The science of yoga: the risks and the rewards. New York: Simon \& Schuster. 